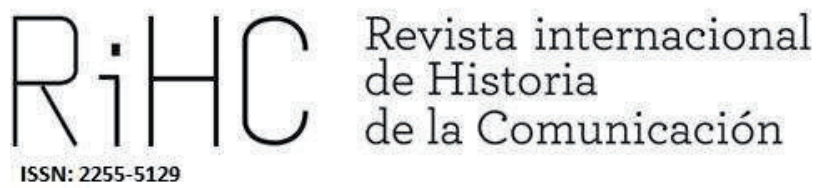

\title{
ROMPIENDO MOLDES: MARÍA LUZ MORALES Y LA CRÓNICA FEMENINA
}

Breaking the mold: María Luz Morales and the female chronicle

DOI: http://dx.doi.org/10.12795/RiCH.2021.i16.04

Recibido: 31-3-2021

Aceptado: 28-5-2021

Publicado: 30-6-2021

María Arroyo Cabello

Universidad Católica de Murcia, España

msarroyo@ucam.edu

ORCID (D) 0000-0001-9896-9263 
Resumen: María Luz Morales pertenece a una generación de periodistas y escritoras recientemente descubiertas por los investigadores. Precursora del periodismo cultural, su prolífica obra la convierte en un referente en la historia del periodismo. El propósito de este trabajo es recopilar las crónicas tituladas Charlas publicadas en la sección "La Mujer, el Niño y el Hogar» de El Sol, además de estudiar su aportación a la modernización de la mujer por la vía de la cultura. Para ello se ha consultado El Sol entre 1926 y 1931 en la Hemeroteca Digital de la Biblioteca Nacional, revisado la literatura científica y efectuado un análisis de contenido. El análisis revela que, si bien los temas coinciden con los contenidos habituales de las revistas femeninas, sin embargo, difieren en el enfoque. El eje temático de las crónicas gira en torno a la literatura escrita por mujeres, literatura infantil, lectura, teatro y moda. La autora fomenta la promoción cultural de la mujer y reclama para ella una consideración intelectual de igualdad.

Palabras clave: María Luz Morales, periodismo, literatura, precursora, crónica femenina

\begin{abstract}
María Luz Morales belongs to a generation of journalists and writers recently discovered by researchers. A forerunner of cultural journalism, her prolific work makes her a benchmark in the history of journalism. The purpose of this work is to compile the chronicles entitled "Talks» published in the section "The Woman, the Child and the Home» of El Sol, in addition, to studying her contribution to the modernization of women through culture. Issues of El Sol between 1926 and 1931 in the Digital Newspaper Library of the National Library were consulted, the scientific literature was reviewed and an analysis of the content was fulfilled. The analysis reveals that while the topics coincide with the usual contents of women's magazines, they nevertheless differ in focus. The thematic axis of the chronicles revolves around literature written by women, children's literature, reading, theater and fashion. The author encourages the cultural promotion of women and demands for her an intellectual consideration of equality.
\end{abstract}

Keywords: María Luz Morales, journalism, literature, forerunner, female chronicle

\title{
Introducción
}

María Luz Morales pertenece a una generación de escritoras y periodistas apenas descubierta por los investigadores que, sin embargo, tuvo una presencia relevante en el ambiente intelectual de su época y participó junto a otras escritoras en iniciativas culturales colectivas. Precursora, vanguardista y promotora del periodismo cultural, su prolífica obra periodística y literaria la convierte en una mujer de referencia en la historia del periodismo, aunque su figura no se incluya en los manuales.

Existen breves biografías en repertorios biográficos, por ejemplo, Rodrigo (1996), Martínez, Reyna Pastor, De la Pascua y Tavera (2000), Mangini (2001), García-Albí (2007), Altés (2007), Luengo, J. (2008), Díaz Nosty (2020), así como una biografía de Mạ 
Ángeles Cabré (2017) y una Tesina de máster (Doespiritusanto, 2011). Asimismo, los estudios sobre su obra han aumentado en los últimos años, como los artículos de Hurtado (2006), Servén (2010, 2012a, 2012b, 2013a y 2013b), Julio (2017), Salgado y Lázaro (2019), entre otros. Por otra parte, es fácil encontrar perfiles suyos en artículos periodísticos y en páginas webs especializadas en historia, cultura gallega o escritoras.

Ahora bien, la mayor parte de estos trabajos se han abordado desde la literatura o la filología; si bien hay un estudio desde el periodismo de Servén (2012a) sobre la sección "La Mujer, el Niño y el Hogar» de El Sol, la presente investigación aporta la recopilación de las crónicas, un análisis de contenido y muestra su visión de la mujer en una época en la que no se reconocía la capacidad intelectual de las mujeres (González Naranjo, 2015).

Preguntada en una entrevista si se consideraba una pionera de las mujeres periodistas respondió: "Sí. En mi época había escritoras, pero no periodistas, en el sentido activo de la palabra. Las mujeres escribían en los periódicos, en las revistas, pero no participaban en las tareas de un periódico como se hace hoy día» (Balaguer,1971:35).

Se trata de una autora que publicó más de mil artículos en periódicos y revistas femeninas, aparte de la inmensa producción narrativa, traductora y editorial, y cultivó todos los géneros periodísticos, en alguno de los cuales fue pionera, como la crítica cinematográfica.

\section{Objetivos y metodología}

Este artículo busca contribuir a difundir la producción periodística de María Luz Morales destinada al público femenino, que se encuentra dispersa en periódicos y revistas femeninas como El Hogar y La Moda, La Vanguardia, El Sol o el Diario de Barcelona, una labor de más de cincuenta años que reclama un estudio pormenorizado.

Los objetivos de este trabajo son la recopilación de las crónicas firmadas tituladas Charlas, publicadas en la sección "La Mujer, el Niño y el Hogar» de El Sol, y el análisis de contenido para conocer su pensamiento y el prototipo femenino que la periodista brindó.

Para la antología se ha consultado El Sol entre 1926 y 1931 en la Hemeroteca Digital de la Biblioteca Nacional. El resultado han sido 168 crónicas, que constituyen el corpus de la investigación, la primera el 4 de diciembre de 1926 y la última el 3 de noviembre de 1931, si bien la sección continúa con otras firmas. 
Tras la revisión hemerográfica, dada la afinidad de contenidos y el espacio limitado del artículo, se optó por clasificar las 168 crónicas en cinco grupos temáticos: Mujer y literatura, Mujer e infancia, Feminismo, Feminidad y Cultura. A continuación, se elaboraron las cinco tablas con las crónicas y se procedió al análisis de contenido cualitativo para conocer la opinión de María Luz Morales respecto a los asuntos tratados.

\section{Semblanza}

La figura de María Luz Morales bascula entre el misterio y la discreción. Para empezar, el año de su nacimiento es un enigma, por lo que los autores barajan distintas fechas según las fuentes utilizadas: en su DNI figura 1898 (Salgado y Lázaro, 2019: 123), en su partida de defunción consta 1890 (Julio,2017: 56) y por el expediente judicial de 1940 sería 1895 (Salgado y Lázaro, 2019: 123). Su biógrafa señala 1889 (Cabré, 2017: 17) y Servén (2013a) apunta a 1898.

Por otro lado, siendo la gran dama del periodismo de su tiempo y teniendo una intensa vida social en ambientes culturales, poco ha trascendido de su vida personal, soltera vivía con su madre en la Gran Vía de les Corts Catalanes 623 (Cabré, 2017: 127) rodeada de sobrinos-, estuvo siempre volcada en su trabajo, que practicó con fruición. Seguramente no se casó para entregarse por entero a su profesión, difícil de compartir con el cuidado de un hogar. María Luz era una mujer discreta, celosa de su intimidad, que empleaba su tiempo en escribir, acudir diariamente al periódico y asistir a los actos culturales en la ciudad condal.

De familia acomodada de La Coruña, pronto abandonaría su ciudad natal para seguir los destinos de su padre, funcionario de Hacienda, hasta que se asentó como administrador en la Delegación de Hacienda de Barcelona, donde transcurrió el resto de su vida. Recibió una formación muy completa, hablaba varios idiomas y poseía una vasta cultura humanística, lo que le permitió desarrollar una imponente carrera periodística, literaria, ensayística y traductora. Inició sus estudios en el Instituto de Cultura francesa Bonnemaison y en el seminario de Pedagogía creado por el Consell de Pedagogia de la Diputación de Barcelona, cursando después Filosofía y Letras en la Universidad Nova.

A la muerte de su padre, por necesidades familiares, comenzó a trabajar muy joven, en 1920, en la revista femenina El Hogar y La Moda y tres años después se convirtió en su directora. En 1921 empieza a colaborar en La Vanguardia y «llama la atención que María Luz Morales no debutase en el matutino barcelonés dentro de una sección femenina, sino en la página de artículos nobles del diario, entre la 5 y la 6 ». Conviene 
aclarar que «la página 5 era la primera página no comercial del diario y recogía normalmente dos o tres artículos firmados por importantes figuras del diario» (Salgado y Lázaro, 2019:124). Por entonces era habitual que a las mujeres se les confiaran los contenidos llamados "femeninos", en eso como en otras cosas la periodista rompió moldes. Al año siguiente se hace cargo de la crítica cinematográfica en una sección semanal "Vida cinematográfica» con el seudónimo galdosiano de Felipe Centeno. A partir de 1933 se ocupó de la crítica de teatro, más valorada y su gran pasión, pero ya firmaba con su nombre. En 1924 es contratada por El Sol, el periódico de los intelectuales, para una crónica dominical en la sección "La Mujer, el Niño y el Hogar», destinada al público femenino.

Simultánea a su faceta periodística transcurre la de escritora: entre 1923 y 1930 hizo la adaptación de los clásicos de la literatura universal para niños en la editorial Araluce ${ }^{1}$ y publicó biografías de mujeres ilustres: Las románticas 1830-1930, entre otras Madame Staël. Actividad que fomentó en la postguerra cuando se vio privada del ejercicio del periodismo, y continuó escribiendo hasta pocos días antes de su fallecimiento en 1980.

Independientemente de su trabajo profesional participó en iniciativas culturales colectivas. En 1931 intervino en la fundación de dos instituciones femeninas: el Lyceum Club de Barcelona y la Residencia de Señoritas de Pedralbes, que fueron espacios de libertad, educación y encuentro para muchas mujeres en los años treinta.

El Lyceum Club de Barcelona vino a sumarse a los existentes en otras ciudades europeas y americanas: Londres (1904), Berlín (1905), París (1906), Nueva York (1914) o Madrid (1926) con idénticos objetivos y en respuesta a la demanda de mujeres intelectuales, escritoras y artistas de contar con un lugar donde compartir inquietudes, experiencias y promover el desarrollo educativo, cultural y profesional de la mujer. En su fundación intervinieron Carmen Monturiol y Aurora Bertrana, como presidenta, y María Luz Morales de vicepresidenta, entre otras. En su Manifiesto fundacional, que fue publicado en varios medios, proclamaba sus intenciones:

Nuestro grupo no aspira a ser otra sociedad más donde las mujeres de inteligencia más o menos selecta se reúnen para tomar una taza de té, hojear una revista, escuchar una pequeña conferencia o un concierto íntimo, ni tampoco a convertirse en un grupo de mujeres indignadas, más o menos santas, que quieren luchar contra el hombre, reclamar todo tipo de derechos $y$ enarbolar la bandera del más feroz feminismo. Ni una cosa ni otra, sino un poco de cada (Manifiesto a las mujeres, Barcelona, 7-julio-1931).

En su breve existencia, en el Lyceum Club se programaron ciclos de conferencias sobre educación, feminismo, voto femenino, legislación, salud; cursos de literatura,

\footnotetext{
${ }^{1}$ La colección Las obras maestras al alcance de los niños fue declarada «de utilidad pública y uso para Bibliotecas Circulantes» y varias veces premiada (Servén, 2012b:13).
} 
gramática catalana, divulgación musical, decoración; sesiones de teatro y poesía y la publicación de libros. La guerra civil puso fin a este oasis de libertad, cultura y amistad para las mujeres de la burguesía catalana.

Otra institución en la que tuvo un papel significativo fue la Residencia Internacional de Señoritas Estudiantes, inaugurada en febrero de 1931 para albergar a jóvenes universitarias. Similar a la madrileña, que desde 1926 dirigía María de Maeztu, para la Residencia de Pedralbes (Barcelona) fue elegida directora María Luz Morales. Durante los seis años que funcionó se organizaron cursos, conciertos, visitas culturales, cursillos formativos o especializados, lecturas poéticas -en las que en más de una ocasión intervino María Luz-, representaciones teatrales, musicales y de danza a cargo de las propias residentes; además de excursiones mensuales y conferencias semanales sobre arte, literatura o biología impartidas por prestigiosas personalidades.

La Residencia ofertaba sesenta plazas, quince de ellas a becarias. Las instalaciones contaban con biblioteca, laboratorios, campos de tenis y gimnasio, aparte de los jardines del palacio. Todo este conjunto creó un ambiente acogedor, culto y armonioso que, en gran medida, se debía a su directora. Ana María Martínez - Sagi, en un artículo sobre la Residencia de Pedralbes, recordaba el fino y cultivado espíritu que María Luz Morales infundía a aquel lugar (1932: 8).

En 1936 las dos instituciones tuvieron que cerrar y después de la guerra no volvieron a abrir. En agosto, por azares de la vida, María Luz se convirtió en la primera mujer en dirigir un periódico en España tras incautarse la Generalitat de La Vanguardia y recaer el control del periódico en la CNT-UGT, cuyo comité de trabajadores del diario la eligió para suceder al anterior director en el exilio, Gaziel. Aceptó, pero dejando claro que su trabajo sería exclusivamente periodístico y su nombramiento provisional. Mucho tiempo después en una entrevista rememorando este episodio decía: "La mía fue una misión de servicio al propio periódico, meramente profesional, y en modo alguno política, con el único fin de que pudiera aparecer cada mañana. Esta circunstancia me causó las dificultades inherentes a todos aquellos que durante esos tres años continuaron en sus puestos» (Balaguer, 1971: 35).

En efecto, al acabar la guerra fue apartada del periodismo hasta su rehabilitación en los años cuarenta y, aunque no dejó de publicar, hubo de recurrir a los seudónimos de Ariel y Jorge Marineda. En 1948 recupera su condición de periodista, es readmitida en el Registro Oficial de Periodistas ${ }^{2}$ y se incorpora a la redacción del Diario de Barcelona para encargarse de las crónicas de teatro y moda y allí permaneció hasta su jubilación. La moda fue junto al teatro y el cine una de sus debilidades, a la que dedicó una monumental Historia de la moda (1928) en doce volúmenes en colaboración con Max von Boehn para la editorial Salvat. Llegó a ser una experta en esta materia, ocupando 
un puesto relevante en el Círculo de escritores de $\operatorname{Moda}^{3}$ y fue delegada de la Asociación Internacional de Prensa Familiar y Femenina.

A la par de una extraordinaria carrera periodística desarrolló una polifacética carrera de escritora para todo tipo de públicos: adultos, jóvenes y niños; cultivó varios géneros: novela, teatro, historia, ensayo y biografía; codirigió distintas colecciones, adaptó los clásicos al mundo infantil y juvenil y tradujo numerosos títulos ${ }^{4}$.

Además, participó en proyectos editoriales: en 1941 fundó la editorial Surco, donde tradujo cincuenta y dos obras. Dirigió tres enciclopedias en la editorial Salvat: Universitas. Enciclopedia de iniciación cultural (1943) en veinte volúmenes, la ya citada Historia de la moda y la Historia ilustrada del séptimo arte (1950) en tres volúmenes. En la editorial Argós (1952) dirigió una Enciclopedia del hogar también en tres volúmenes, sin olvidar las conferencias que pronunció durante décadas, donde mostró un saber casi enciclopédico.

Tarín-Iglesias dijo de ella:

María Luz Morales es una figura indiscutible, no sólo del periodismo, sino incluso de nuestras letras, puesto que ha tenido la rara virtud de cultivar todos los géneros literarios $y$, todos ellos, con verdadero éxito. Desde los días del inolvidable $\mathrm{El} \mathrm{Sol}$, con toda su inmensa carga intelectual, pasando por los de $L a$ Vanguardia hasta llegar al Diario de Barcelona, media toda una vida, que silenciosamente ha recorrido con suprema dignidad (1973:15).

En su madurez recibió numerosos premios y condecoraciones: la Croix de Chevalier de la orden de las Palmas Académicas Francesas (1956), Premio Nacional de Teatro (1962), Premio Eugenio D’Ors de la Asociación de la Prensa de Barcelona (1970) ${ }^{5}$, Lazo de Dama de la orden de Isabel la Católica (1971) ${ }^{6}$, Premio de Periodismo Ciudad de Barcelona (1972), Premio Ramón Godó Lallana de Periodismo (1973) y la Medalla al Mérito en el Trabajo (1976) en su categoría de plata.

Fue homenajeada en 1965 al convertirse en decana de los periodistas españoles, en sus Bodas de Plata (1946) y en sus Bodas de Oro (1971) con el periodismo, sin contar los actos organizados en su honor por asociaciones teatrales, literarias o del círculo de la moda.

3 En 1960 fue presidenta del jurado del premio Miss Paraguas y en 1974 recibió el premio Lanzadera de Honor, con el que se galardonaba a las personalidades destacadas del mundo de la moda (Cabré, 2017: 93).

4 Tradujo al castellano a autores catalanes y extranjeros, obras de teatro, etc., que recoge Teresa Julio (2017) en su estudio específico sobre María Luz Morales traductora.

5 Este premio era la primera vez que se concedía a una mujer.

6 Otorgado con ocasión de sus Bodas de Oro con la profesión siendo la primera mujer periodista en recibir la condecoración. 
Una mujer que estuvo reconocida por sus contemporáneos, pero olvidada después, es ahora cuando se está estudiando su pensamiento y su obra, coincidiendo con iniciativas para honrar su memoria. En 2016 la Fundación La Caixa, La Vanguardia y el Observatorio Cultural de Género instituyeron el Premio de Periodismo María Luz Morales para trabajos sobre el papel de la mujer en el mundo actual. Y en 2017 la Academia Gallega del Audiovisual creó el Premio María Luz Morales para la investigación audiovisual.

\section{Resultados y discusión: una feminidad renovada}

Cuando en 1926 El Sol inicia una sección destinada al público femenino titulada "La Mujer, el Niño y el Hogar» hacía unos años que la prensa, dándose cuenta del formidable potencial que suponían las lectoras, venía publicando una página semanal con contenidos denominados "femeninos» ${ }^{7}$. El Sol, un periódico «dirigido a la conquista de públicos interesados por la política, la cultura y los negocios», pero "con vocación también de llegar a un público numeroso» (Cabrera, 1994: 98), encargó a María Luz Morales, ya una reputada periodista, una crónica dominical para esa sección.

Si en El Hogar y la Moda María Luz se había ocupado del espacio tradicional de la mujer, el entorno doméstico y algunas reseñas de libros, ahora en El Sol se propuso atraer la atención de las mujeres hacia temas no específicamente femeninos pero que consideraba de interés para ellas, como dejó claro en su primera crónica:

En esta página que la dirección de El Sol pone en mis manos, todavía inexpertas, una mujer va a hablar, en semanal charla amiga, de las cosas que a las mujeres interesan: del hogar, del niño, de la casa, del ambiente doméstico, de hijos. Y también, ¿por qué no? De trapos, de modas, de afeites, de gratas y consoladoras frivolidades... Y también, en cuanto la fuerza y la voz de quien ha de hablar a ella alcancen, de los eternos temas humanos que por igual a hombres y mujeres importan: la belleza, el trabajo, la cultura, el arte, la naturaleza, el dolor, la caridad. De la Mujer, del Niño, del Hogar... ¿No están la vida, el hombre, el mundo en esas tres palabras? Que lo arriesgado, lo pretencioso del empeño se me perdone, en gracia a que siempre han de venir conmigo Madonna Sencilla y Madonna Sinceridad (El Sol, 4-diciembre-1926, p.8).

\footnotetext{
${ }^{7} A B C$ sacaba un suplemento semanal titulado "La Mujer y la Casa» y "La Madre y el Niño» (Seoane y Sáiz, 1998: 192).
} 
Por otra parte, la temática de las crónicas de María Luz Morales en «La Mujer, el Niño y el Hogar» coincide con los contenidos de las publicaciones femeninas de la época en que

pueden dar cabida en sus páginas a temas culturales o dedicar alguna atención a reivindicaciones feministas, para rechazarlas o para aceptar un feminismo «moderado». De hecho, no pueden dejar de reflejar el cambio que se ha producido en la vida de las mujeres y que se evidencia sobre todo a partir de los años veinte (Seoane y Sáiz 1998: 189).

Sin embargo, la peculiaridad de María Luz Morales es el tratamiento que hace de los temas desde su conocimiento de las grandes figuras de la literatura universal, sobre todo de la literatura escrita por mujeres.

Acerca de estos asuntos tratan las 168 crónicas que desde el 4 de diciembre de $1926^{8}$ hasta el 3 de noviembre de 1931 aparecieron los domingos bajo el epígrafe "Mujeres» y «Charlas» en las páginas 9 y 10 del periódico. En los tres primeros años se mantiene la frecuencia semanal, que se interrumpe en 1930, habiendo tres meses en los que no escribe y apenas lo hace en el último año en el que publica sólo siete piezas.

Las crónicas (Imagen 1), siempre firmadas, solían tener entre 1100 y 1400 palabras de extensión y se ubicaban en las dos o tres columnas de la izquierda de las ocho que componían la página. Un espacio femenino con distintos apartados: niños, casa, moda, una guía práctica con consejos, la crónica femenina, un cuento ilustrado y publicidad. El diseño a tres columnas de la cabecera se componía del título con ilustraciones en el centro de la página; al comienzo de 1931 cambió la tipografía a ocho columnas y sin ilustraciones.

8 Su colaboración se venía anunciando en La Voz y El Sol junto a otros intelectuales del momento como Ortega y Gasset y Ramiro de Maeztu, lo que muestra el nivel que María Luz Morales había alcanzado cuando El Sol decide contratarla (Servén, 2012a: 1067). 


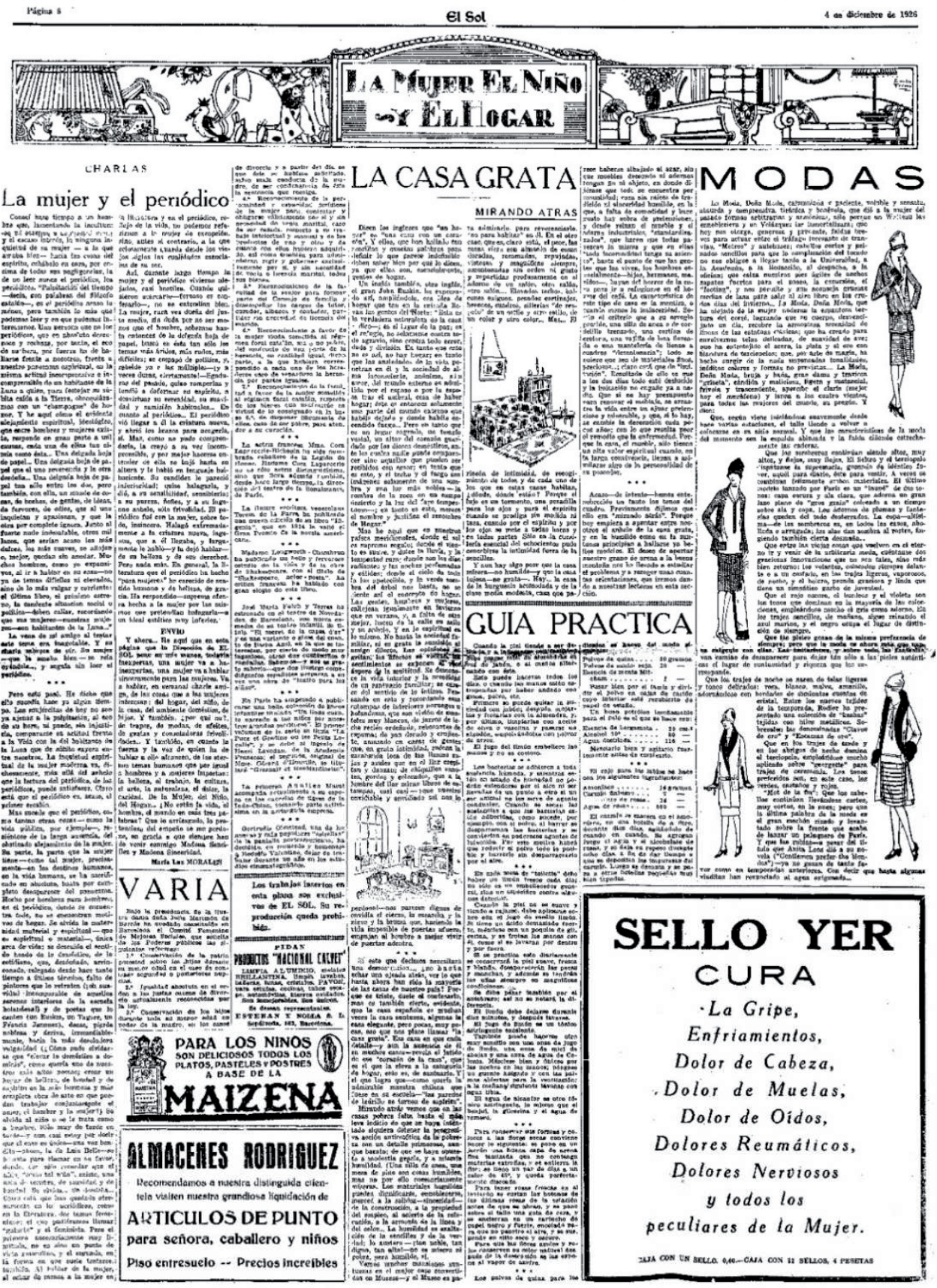

Imagen 1. El Sol, 4-diciembre-1926, p.8

Se trata de una página destinada al público femenino, escrita con un estilo literario culto y erudito que, por otra parte, sintoniza con el tono intelectual de El Sol.

A finales de 1931 desaparece la firma de la periodista y la sección «La Mujer, el Niño y el Hogar», tras un año de indefinición, el 25 de diciembre de 1932 recupera la normalidad (Imagen 2). La moda cobra protagonismo, se mantienen los temas de higiene-belleza, decoración, el cuento, la publicidad y una tira cómica. La escritora Carmen de Icaza, con el seudónimo «CIL», sustituye a María Luz Morales. 
El Sol

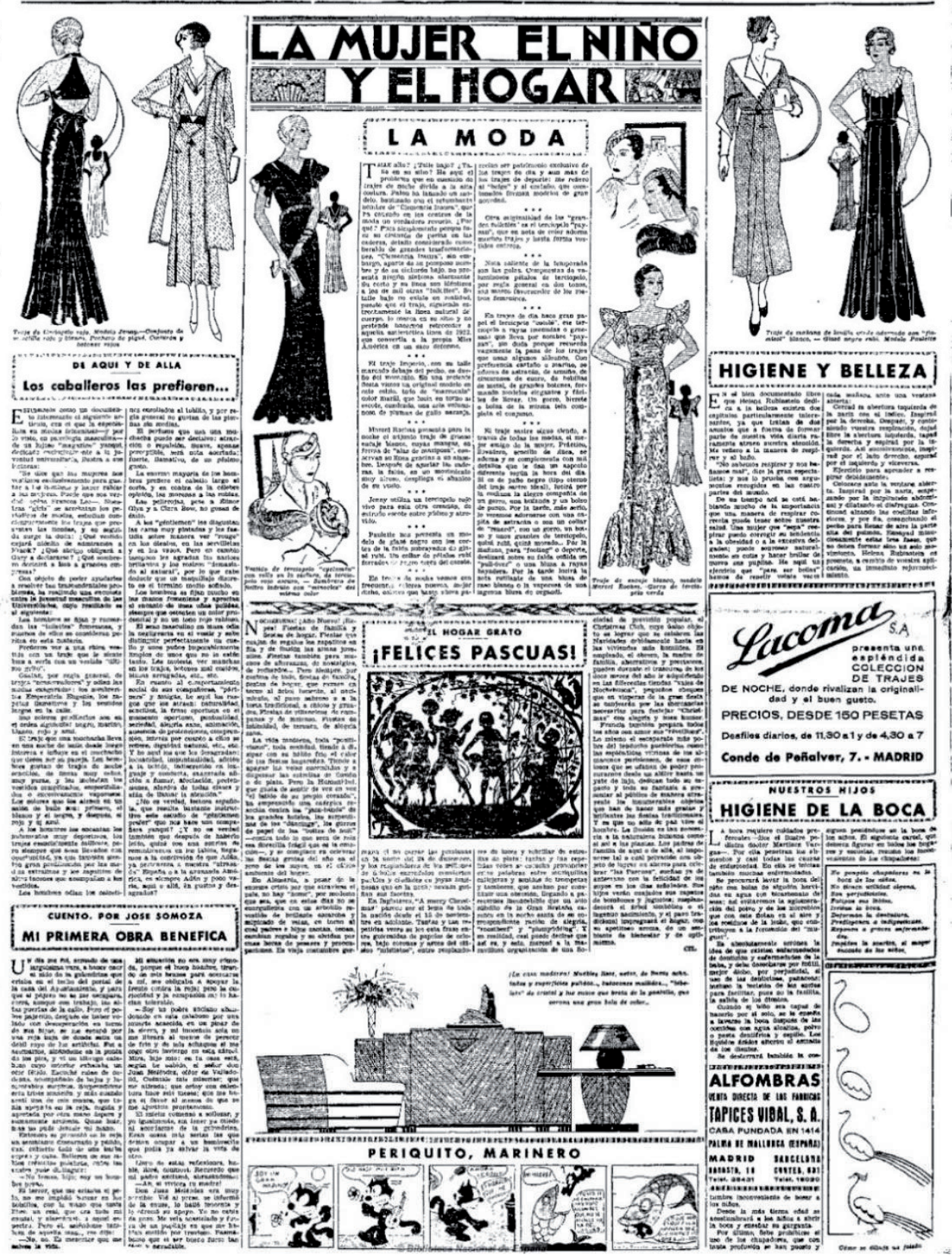

Imagen 2. El Sol, 25-diciembre-1932, p.10

A continuación, exponemos los resultados del análisis de los cinco grupos temáticos en los que se dividieron las 168 crónicas y las cinco tablas correspondientes con la recopilación de los textos. Tabla 1, Mujer y literatura; tabla 2, Mujer e infancia; tabla 3, Feminismo; tabla 4, Feminidad; y tabla 5, Cultura.

El análisis de Mujer y literatura (tabla 1) revela que María Luz Morales realizó una importante tarea de difusión entre sus lectoras de la literatura escrita por mujeres, dedicando cincuenta crónicas a escritoras de todos los tiempos. Con ocasión del centenario del movimiento romántico en 1927 hizo una serie de dieciocho crónicas, que se publicaron entre el 16 de septiembre de 1927 y el 19 de febrero de 1928 y, tres 
años después, aparecieron como libro, Las románticas. Además, escribió dos crónicas sobre la poetisa mexicana sor Juan Inés de la Cruz y tres referentes a la estancia de George Sand en la Cartuja de Valldemosa (Mallorca), sus discusiones con Chopin y sus paseos por la isla.

Entre las escritoras españolas está Víctor Catalá, seudónimo de Caterina Albert, cuyos cuentos había traducido para El Sol en 1928 y 1929. Ahora, a petición del director del periódico intercedió para que la escritora catalana aceptase colaborar con el diario (Hurtado, 2006: 47).

Del mismo modo, que escribió sobre autoras, lo hizo de personajes femeninos de la literatura; así, el 17 de febrero de 1929 dedicó una crónica a "Las hijas de Valdemar» de Christian Andersen, relato que le gustaba por el análisis de la feminidad. Y el 2 de abril de 1927 se lamentaba de que en la literatura actual no hubiera personajes tan nobles como algunas protagonistas literarias, por ejemplo, Dulcinea, Doña Inés, Porcia, Penélope, Amy Dorrit...

Con el fin de animar a la lectura de la historia, destinó algunas piezas a mujeres ilustres, como Concepción Arenal. Con ocasión de la iniciativa de algunas mujeres intelectuales de erigirle un monumento en Madrid, el 13 de mayo de 1928 escribió una crónica elogiosa del personaje y de la propuesta femenina. Del mismo modo, a la muerte en 1927 de la princesa Carlota de Sajonia, luego emperatriz de México, redactó tres piezas donde cuenta su interesante historia y su triste final.

Carmen Servén (2012a: 1068) alaba su importante labor como difusora de la literatura en las páginas de El Sol, así como la encuesta, de la que se hicieron eco otros periódicos.

En efecto, por iniciativa de María Luz Morales y con el fin de averiguar los gustos literarios de las mujeres, el 16 de abril de 1927 se anunciaba en la sección «La Mujer, el Niño y el Hogar» una encuesta sobre ¿qué leen las mujeres? con cuatro preguntas: ¿qué lee usted, señora o señorita?, ¿cuál es su género literario predilecto?, ¿a cuál autor vivo o muerto, nacional o extranjero admira usted más? y ¿qué tres libros considera indispensables en su biblioteca? Encuesta que volvió a publicitarse el día 23 en la misma página junto a la crónica habitual de María Luz Morales, a quien habían de dirigirse las respuestas.

El 7 de mayo, aparecen los primeros resultados, a saber, la alta participación de las lectoras, la ignorancia de muchas mujeres de clase media -a quienes se dirigía la encuesta-, y el afán de saber y la curiosidad de las encuestadas. El 28 se ofrecían algunos datos concluyentes: el $70 \%$ eligen la novela, el autor más leído es Benito Pérez Galdós y entre los tres libros indispensables sorprende que no se encuentre ninguna obra de su autor preferido. Los resultados de la encuesta «evidencian una gran 
desorientación y un deseo todavía mayor de orientarse en materias de lecturas por parte de un gran número de mujeres españolas» (Servén, 2012a: 1068).

El 4 de junio María Luz se dirige al director de la Biblioteca Nacional para averiguar cuáles son los libros más solicitados por las mujeres y el 11 de julio hace una tercera encuesta, esta vez a prestigiosos intelectuales. Las preguntas son dos: qué deberían leer las mujeres y cuáles son los libros que no deben faltar en una biblioteca. Los resultados son poco gratificantes: «las mujeres leen poco, deberían leer lo mismo que los hombres y no deberían limitarse a la llamada literatura blanca, ñoña o sensiblera que algunos hacen a su medida» (EI Sol, 31-julio-1927, p.9). "La opinión mayoritaria de los intelectuales consultados parece contraria a una diversificación de lecturas que propicie diferencias de género en el material literario» (Servén, 2012a: 1069).

Con todo, María Luz se muestra satisfecha por haber despertado el interés de las mujeres por la lectura. El tema había acaparado la atención de las lectoras durante cuatro meses.

\section{Tabla 1. Mujer y literatura}

\begin{tabular}{|c|c|c|}
\hline Título & Fecha y página & Temática \\
\hline Una mujer y un libro & El Sol, 18/12/1926, p.9 & Literatura escrita por mujeres \\
\hline Perfil de una sombra I & El Sol, 5/2/1927, p.9 & Mujeres ilustres \\
\hline Perfil de una sombra II & El Sol, 12/2/1927, p.9 & Mujeres ilustres \\
\hline Perfil de una sombra III & El Sol, 19/2/1927, p.9 & Mujeres ilustres \\
\hline $\begin{array}{l}\text { Mujeres. Amadas de } \\
\text { Beethoven }\end{array}$ & El Sol, 26/3/1927, p.9 & Mujeres de hombres ilustres \\
\hline Charlas. El Espejo Literario & El Sol, 2/4/1927, p.9 & $\begin{array}{l}\text { Personajes femeninos de la } \\
\text { literatura }\end{array}$ \\
\hline $\begin{array}{l}\text { Mujeres. Anita Loos o lo } \\
\text { intrascendente }\end{array}$ & El Sol, 16/4/1927, p.9 & Literatura escrita por mujeres \\
\hline $\begin{array}{l}\text { Charlas. Paisaje, amory } \\
\text { literatura I }\end{array}$ & El Sol, 14/5/1927, p.9 & Literatura escrita por mujeres \\
\hline $\begin{array}{l}\text { Charlas. Paisaje, amor y } \\
\text { literatura II }\end{array}$ & El Sol, 21/5/1927, p.9 & Literatura escrita por mujeres \\
\hline $\begin{array}{l}\text { Charlas. Paisaje, amor y } \\
\text { literatura III }\end{array}$ & El Sol, 28/5/1927, p.9 & Literatura escrita por mujeres \\
\hline $\begin{array}{l}\text { Mujeres. Timidez y osadía } \\
\text { literarias }\end{array}$ & El Sol, 21/8/1927, p.9 & Literatura escrita por mujeres \\
\hline Mujeres. Isadora o la danza & El Sol, 25/9/1927, p.9 & Mujeres ilustres \\
\hline Mujeres románticas I & El Sol, 16/9/1927, p.9 & Literatura escrita por mujeres \\
\hline $\begin{array}{l}\text { Mujeres románticas II. } \\
\text { Madame de Stael }\end{array}$ & El Sol, 23/10/1927, p.9 & Literatura escrita por mujeres \\
\hline
\end{tabular}


Mujeres románticas III.

Madame de Stael II

Mujeres románticas IV. Ellas y

él

Mujeres románticas $\mathrm{V}$. Lucila o el enigma

Mujeres románticas VI.

Marcelina o la feminidad

Voto de gracias

Mujeres románticas VII.

Marcelina o la feminidad II

Mujeres románticas VIII.

Vagas siluetas

Mujeres románticas $\mathrm{X}$.

Heroína

Mujeres románticas XII. Tras la cortina

Mujeres románticas XIII. EI

telón afuera

Mujeres románticas XIV.

Esbozo

Mujeres románticas XV. La

última novia de don Juan

Mujeres románticas XVI

Mujeres románticas XVII.

Postromanticismo femenino

Mujeres románticas XVIII y

último. La herencia

Mujeres. Ella y su estatua

Mujeres. Goyesca

Mujeres. La vida amorosa de...

Mujeres. Poetisas de América

Mujeres. Poetisas de América

II

Mujeres. Final feliz

Navidad. Villancicos

El cuento de Reyes.

Sensibilidad y literatura

Mujeres. Una vez...
El Sol, 30/10/1927, p.9 Literatura escrita por mujeres

El Sol, 6/11/1927, p.9 Literatura escrita por mujeres

El Sol, 13/11/1927, p.9 Literatura escrita por mujeres El Sol, 20/11/1927, p.9 Literatura escrita por mujeres El Sol, 20/11/1927, p.9 Literatura, periódico

El Sol, 27/11/1927, p.9 Literatura escrita por mujeres

El Sol, 4/12/1927, p.9 Literatura escrita por mujeres

El Sol, 18/12/1927, p.9 Literatura escrita por mujeres

El Sol, 2/1/1928, p.9 Literatura escrita por mujeres

El Sol, 15/1/1928, p.9 Literatura escrita por mujeres

El Sol, 22/1/1928, p.9 Literatura escrita por mujeres

El Sol, 29/1/1928, p.9 Literatura escrita por mujeres

El Sol, 5/2/1928, p.9 Literatura escrita por mujeres

El Sol, 12/2/1928, p.9 Literatura escrita por mujeres

El Sol, 19/2/1928, p.9 Literatura escrita por mujeres

El Sol, 13/5/1928, p.9 Mujeres ilustres

El Sol, 1/7/1928, p.10 Literatura

El Sol, 7/10/1928, p.10 Mujeres en la literatura

El Sol, 4/11/1928, p.10 Literatura escrita por mujeres

El Sol, 11/11/1928, Literatura escrita por mujeres p.10

El Sol, 27/12/1928, Literatura escrita por mujeres p.10

El Sol, 23/12/1928, Literatura

p.10

El Sol, 6/1/1929, p.10 Literatura

El Sol, 13/1/1929, p.10 Literatura escrita por mujeres 


\begin{tabular}{|c|c|c|}
\hline $\begin{array}{l}\text { Mujeres. Las hijas de } \\
\text { Valdemar }\end{array}$ & El Sol, 17/2/1929, p.10 & $\begin{array}{l}\text { Personajes femeninos de la } \\
\text { literatura }\end{array}$ \\
\hline $\begin{array}{l}\text { Mujeres. Rachilde. La moda. El } \\
\text { feminismo }\end{array}$ & El Sol, 21/4/1929, p.10 & Literatura escrita por mujeres \\
\hline $\begin{array}{l}\text { Mujeres. Preciosas y } \\
\text { preciosismo }\end{array}$ & El Sol, 15/9/1929, p.10 & Literatura \\
\hline Mujeres. Amistad a los poetas & $\begin{array}{l}\text { El Sol, 13/10/1929, } \\
\text { p.10 }\end{array}$ & Literatura escrita por mujeres \\
\hline $\begin{array}{l}\text { Mujeres. La princesa aventura } \\
\text { I }\end{array}$ & $\begin{array}{l}\text { El Sol, 27/10/1929, } \\
\text { p.10 }\end{array}$ & Mujeres ilustres \\
\hline $\begin{array}{l}\text { Mujeres. La princesa aventura } \\
\text { II }\end{array}$ & El Sol, 3/11/1929, p.10 & Mujeres ilustres \\
\hline Mujeres. Frente a don Juan & $\begin{array}{l}\text { El Sol, 17/11/1929, } \\
\text { p.10 }\end{array}$ & Literatura \\
\hline Bienvenida poesía & El Sol, 19/1/1930, p.10 & Literatura escrita por mujeres \\
\hline Mujeres. Invocación & El Sol, 17/8/1930, p.10 & Mujeres ilustres \\
\hline $\begin{array}{l}\text { Libros de mujeres. Aurora de } \\
\text { Polinesia }\end{array}$ & El Sol, 21/3/1931, p.10 & Literatura escrita por mujeres \\
\hline Mujeres. Una profecía & El Sol, 10/5/1931, p.10 & Literatura escrita por mujeres \\
\hline Mujeres. La dama del soneto & El Sol, 27/9/1931, p.10 & $\begin{array}{l}\text { Personajes femeninos de la } \\
\text { literatura }\end{array}$ \\
\hline
\end{tabular}

Acerca de la Mujer y la infancia (tabla 2) escribió diecinueve crónicas, de las que nueve fueron para denunciar la situación de los niños en las Inclusas y reivindicar para ellos una consideración social que no tenían. El 23 y 30 de abril de 1927 describe en dos crónicas la "frialdad» de los Hospicios y el 30 el Comité Femenino de Mujeres Sociales de Barcelona promete estudiar el problema y construir una Casa Materna, donde los niños tengan calor de hogar. Por su parte, el Lyceum Club de Madrid abrirá una Casa de los Niños para hijos de madres trabajadoras (EI Sol, 19-marzo-1927, p.9).

Igualmente, denunció la discriminación que padecían los hijos naturales en una sociedad que estigmatizaba a los hijos concebidos fuera del matrimonio. "La mujer que tiene un hijo no es soltera: es madre nada más» (El Sol, 7-abril-1929, p.10). Otro tema que le preocupó fue la reinserción social de los menores; a propósito de una sentencia condenatoria a un niño de seis años a quince de correccional María Luz opina que los tribunales de menores deben buscar la reinserción y no el odio para toda la vida (EI Sol, 14-julio-1929, p.10)

Por otra parte, se la considera una gran promotora de la lectura infantil que fomenta la afición buscando los libros más apropiados, con adaptaciones de los clásicos, traducciones... Por eso publicó numerosos libros para el público infantil y escribió un 
librito titulado Libros, mujeres, niños... que llegó a repartirse gratis en las escuelas. "La propia María Luz Morales emprenderá esa labor de supresiones levísimas e inteligentes revisiones que permiten poner con éxito en manos infantiles clásicos universales: la Iliada, Shakespeare, Robinson Crusoe o La Gitanilla forman parte de ese repertorio posible» (Servén, 2012b: 6).

«Desde sus trabajos en la prensa, María Luz desarrolló una importante labor como promotora y divulgadora la literatura infantil. Su nombre es repetidamente recordado en numerosas páginas periodísticas como escritora entregada a la consolidación y difusión del libro infantil» (Servén ,2012b: 3).

A la literatura infantil dedicó varias crónicas. En el centenario de Julio Verne en 1928 recomendó su lectura, muy apropiada para niños y jóvenes (El Sol, 18-marzo-1928, p.9). Defendió la presencia de las hadas en los cuentos recordando los numerosos autores que escribieron sobre seres imaginarios a lo largo de la historia de la literatura. (El Sol, 30-junio-1929, p.10). "Se ha concedido primacía decidida al practicismo, a las enseñanzas serias, a los conocimientos útiles, relegando a último término la imaginación, el ensueño, la fantasía. Y no se trata de eso...» (Servén,2012b:5).

Apuesta por la lectura divertida porque para instrucción ya están los libros de texto. «Descarta el utilitarismo directo en la lectura infantil y aborda la lectura de ocio y placer como meta central de la biblioteca escolar del centro» (Servén,2012b:5).

Aconsejaba que en las escuelas se contaran cuentos porque «el relato oral es la más fecunda preparación para el libro». "Por nuestra parte, no sabríamos desear mayor gloria para nuestras gentiles maestritas que esta de cautivar con su arte y con su gracia a todo un auditorio de chiquillos» (EI Sol, 10-marzo-1929, p.10). Igualmente, considera necesaria la colaboración de padres y maestros para la formación en valores de los niños, así como fomentar la lectura en el hogar (El Sol, 19-mayo-1929, p.10). Decía que las madres son excelentes mediadoras en la promoción de la lectura infantil. "Esa forma de concebir la intervención de la madre en la educación de los hijos será una de las constantes de su perspectiva» (Servén, 2012a:1068).

Tabla 2. Mujer e infancia

\begin{tabular}{|c|c|c|}
\hline Título & Fecha y página & Temática \\
\hline El alma del juguete & El Sol, 1/1/1927, p.8 & Niños \\
\hline El alma del juguete & El Sol, 8/1/1927, p.8 & Niños \\
\hline $\begin{array}{l}\text { Charlas. "Lyceum y los } \\
\text { niños" }\end{array}$ & El Sol, 19/3/1927, p.9 & Casa de los Niños, social \\
\hline Mujeres. Las dolorosas I & El Sol, 23/4/1927, p.9 & Niños, inclusas \\
\hline Mujeres. Las dolorosas II & El Sol, 30/4/1927, p.9 & Niños, inclusas \\
\hline
\end{tabular}




\begin{tabular}{|c|c|c|}
\hline $\begin{array}{l}\text { Mujeres. Otra vez la "Casa } \\
\text { de los Niños" }\end{array}$ & El Sol, 18/6/1927, p.9 & Casa de los Niños, social \\
\hline $\begin{array}{l}\text { Los niños. La ruta de Julio } \\
\text { Verne }\end{array}$ & El Sol, 18/3/1928, p.9 & Literatura infantil \\
\hline $\begin{array}{l}\text { El niño en la obra de } \\
\text { Jacinto Benavente }\end{array}$ & El Sol, 3/2/1929, p.10 & Los niños en la literatura \\
\hline $\begin{array}{l}\text { Mujeres. Contemos } \\
\text { cuentos a los niños... }\end{array}$ & El Sol, 10/3/1929, p.10 & Lectura \\
\hline $\begin{array}{l}\text { Mujeres. La casa de los } \\
\text { niños }\end{array}$ & El Sol, 5/5/1929, p.10 & Casa de los Niños, social \\
\hline Mujeres. Otra amistad & El Sol, 19/5/1929, p.10 & Educación infantil \\
\hline $\begin{array}{l}\text { Los chicos. Frente a un } \\
\text { campamento }\end{array}$ & El Sol, 2/6/1929, p.10 & Literatura infantil \\
\hline $\begin{array}{l}\text { Mujeres. Las hadas } \\
\text { aterrizan }\end{array}$ & El Sol, 30/6/1929, p.10 & \\
\hline $\begin{array}{l}\text { Los niños. Aquella } \\
\text { sentencia... }\end{array}$ & El Sol, $14 / 7 / 1929$, p.10 & Niños, leyes \\
\hline $\begin{array}{l}\text { Los niños. Las hadas se } \\
\text { van }\end{array}$ & El Sol, 13/7/1930, p.10 & Niños \\
\hline $\begin{array}{l}\text { Mujeres. La rebelión de } \\
\text { los niños I }\end{array}$ & El Sol, 3/8/1930, p.10 & Niños, social \\
\hline $\begin{array}{l}\text { Mujeres. La rebelión de } \\
\text { los niños II }\end{array}$ & El Sol, 10/8/1930, p.10 & Niños, social \\
\hline $\begin{array}{l}\text { Mujeres. Sed, prohibición } \\
\text { y escuela }\end{array}$ & El Sol, 1/1/1931, p.10 & Educación infantil \\
\hline $\begin{array}{l}\text { Mujeres. iLos niños, los } \\
\text { niños! }\end{array}$ & El Sol, 5/7/1931, p.10 & Niños, social \\
\hline
\end{tabular}

En el primer tercio del siglo XX se desarrolla la polémica feminista que se había iniciado en el siglo XIX y a la que no es ajena María Luz Morales. El Lyceum Club, del que era socia, realizó una intensa campaña para abolir leyes que discriminaban a las mujeres. El Ateneo de Barcelona, del que era asidua, organizó una serie de conferencias de Carme Karr sobre la Educación femenina, reivindicando la intervención de la mujer en la esfera pública, así como la educación para las casadas (Franco, 2004: 474).

Naturalmente, la condición femenina (tabla 3) está presente en la obra periodística de María Luz Morales, no en vano a este asunto destinó dieciséis textos en la sección «La Mujer, el Niño y el Hogar». De ellos seis se refieren al debate feminismo-antifeminismo de los años veinte y treinta. 
El feminismo que preconiza es un feminismo moderado que aboga por el derecho de la mujer al ejercicio de una profesión y un salario justo, a la educación y a la cultura, además de participar en el espacio público. Seguramente, en esta concepción del feminismo influyó Francesça Bonnemaison ${ }^{9}$, defensora del trabajo y educación de las mujeres como base de la emancipación, en cuyo Instituto se formó.

Consideraba el trabajo fuera del hogar un logro de las mujeres al que no se podía renunciar:

No es por afán de lucimiento, no es por amor al lujo ni por ambición desmedida por lo que trabajan las mujeres, es por necesidad sencillamente. El trabajo, con las responsabilidades que de él nacen, es lo que más nos diferencia a nosotras, mujeres de hoy, de las mujeres de ayer, nuestras abuelas. Todas las predicaciones de todos los antifeministas del mundo no lograrán que dejaran de ser esto, que es (EI Sol, 15-enero- 1927, p.8).

Asimismo, estuvo en sintonía con el feminismo que representaba la burguesía ilustrada de Barcelona, a la que perteneció Dolors Monserdà, fundadora en 1911 del Patronato de las obreras de la aguja, tema al que dedicó una crónica "La humilde tarea» (EI Sol, 7-mayo-1927, p.9).

Consideró el Congreso de Mujeres Universitarias celebrado en 1928 en Madrid organizado por la International Federation of University Woman, como el acontecimiento feminista más importante del momento, destacando la intervención de Clara Campoamor, que se convertiría en su presidenta al año siguiente ( $E$ I Sol, 23 de septiembre de 1928, p.10). Lo mismo que mostró su satisfacción por las deliberaciones en Francia del derecho al voto de las mujeres, que en España no se plantearía hasta 1931.

Era contraria al feminismo radical por auspiciar el enfrentamiento entre sexos. Creía en la igualdad de oportunidades, pero no en que hombres y mujeres fueran iguales ( $E$ I Sol, 20-julio-1930, p.10).

Salgado y Lázaro (2019: 131) dicen que: «Morales tampoco aceptaría nunca que el hombre y la mujer sean iguales. Cada cual tiene un ser, si no intangible, de difícil definición, y ninguno de los dos debe salir de sí mismo para intentar ser otro. Pero los dos tienen el mismo valor social. Y la misma necesidad de existencia pública».

\footnotetext{
${ }^{9}$ En los años 20 esta pedagoga creó el Institut de Cultura i Biblioteca Popular per la Dona y, en 1922 una mutualidad para los desempleados, una bolsa de trabajo y una revista femenina Vida Femenina (Franco, 2004: 476).
} 
Tabla 3. Feminismo

\begin{tabular}{lll} 
Título & Fecha y página & Temática \\
\hline Feminismo y trabajo & El Sol, 15/1/1927, p.8 & Trabajo \\
El voto y la mujer normal & El Sol, 29/1/1927, p.9 & Derechos \\
Mujeres. Las machaconas & El Sol, 17/7/1927, p.9 & Derechos \\
Mujeres. "In Memoriam" & El Sol, 24/6/1928, p.9 & Feminismo, \\
& & derechos \\
Al pasar. Paisaje, feminismo, dolor & El Sol, 26/8/1928, p.10 & Derechos \\
Charlas. Cartas a mujeres & El Sol, 2/9/1928, p.10 & Igualdad \\
Mujeres. El don de oportunidad & El Sol, 9/9/1928, p.10 & Feminismo \\
Mujeres. Escuela y paz & El Sol, 16/9/1928, p.10 & Feminismo \\
Mujeres. Salutación & El Sol, 23/9/1928, p.10 & Feminismo \\
Mujeres. La batalla de los sexos & El Sol, 27/1/1929, p.10 & Igualdad \\
$\begin{array}{l}\text { Mujeres. La herencia de mistress } \\
\text { Pankhurst }\end{array}$ & El Sol, 9/6/1929, p.10 & Derechos \\
Mujeres. Hablando con Gianna Basevi & El Sol, 7/7/1929, p.10 & Feminismo \\
Mujeres. Amigas de los libros & El Sol, 26/1/1930, p.10 & Feminismo \\
Mujeres. Los árboles y el bosque & El Sol, 6/4/1930, p.10 & Derechos \\
Mujeres. Dar... & El Sol, 20/7/1930, p.10 & Feminismo \\
Mujeres. Otra vez más... & El Sol, 14/9/1930, p.10 & Derechos \\
\hline
\end{tabular}

María Luz Morales prefería hablar de feminidad más que de feminismo: "yo respeto, simpatizo y me uno al ideal de las feministas en cuanto tienen de ideal femenino" (EI Sol, 16-septiembre-1928, p.10). Escribió cincuenta crónicas (tabla 4) referentes a maternidad, cuidado del hogar, arreglo personal, pero también tocantes a independencia, ejercicio de una profesión, cultivo de aficiones, deporte y moda. Habló del amor a la naturaleza recordando el paisaje de su Galicia natal, criticó los concursos de belleza porque solo valoran el aspecto físico de la mujer, no su belleza interior y elogió el rol de las madres.

Carmen Servén (2012a: 1068) califica su pensamiento tradicional: «Procurará siempre ceñirse a los parámetros comunes en la mentalidad de su tiempo, aunque intentando siempre dignificar el rol femenino y mejorar la formación e información de las mujeres».

Para Salgado y Lázaro (2019: 127) se trata de una modernidad conservadora: «la ocupación del espacio público por parte de la mujer se basa, por un lado, en unas 
capacidades que no se pueden negar y una actitud regeneracionista, pero a la vez, en una esencia femenina que tiene que ver con la entrega y la devoción, una postura claramente conservadora».

La periodista reconoce las ventajas de la modernidad y comprende algunos cambios en las costumbres, por ejemplo: "Las madres de después de la guerra se han modernizado y salen con amigas, bailan, toman una copa, visten a la moda, se cortan el pelo» (El Sol, 16-junio-1929, p.10). Ante los desafíos de la modernidad propone una feminidad renovada con lo bueno de la tradición, pero sin los vicios del pasado; contando con el progreso, libertad e igualdad para su género que traen los nuevos tiempos, pero asumiendo la responsabilidad, el esfuerzo y la eficacia (EI Sol, 9-octubre -1927, p.9).

\section{Tabla 4. Feminidad}

\begin{tabular}{|c|c|c|}
\hline Título & Fecha y página & Temática \\
\hline La mujer y el periódico & El Sol, 4/12/1926, p.8 & Feminidad \\
\hline $\begin{array}{l}\text { Mujeres. Bovarysmo y } \\
\text { modernidad }\end{array}$ & El Sol, 5/3/1927, p.9 & Feminidad, modernidad \\
\hline $\begin{array}{l}\text { Charlas. "El hombre que } \\
\text { gusta a las mujeres" }\end{array}$ & El Sol, 12/3/1927, p.9 & Feminidad, modernidad \\
\hline Charlas. La humilde tarea & El Sol, 7/5/1927, p.9 & Hogar \\
\hline $\begin{array}{l}\text { Mujeres. La tragedia de la } \\
\text { suegra }\end{array}$ & El Sol, 3/7/1927, p.9 & Educación \\
\hline Mujeres. Las domingueras & El Sol, 24/7/1927, p.9 & Feminidad, naturaleza \\
\hline Mujeres. Alas o pezuñas & El Sol, 7/8/1927, p.9 & Educación, danza \\
\hline $\begin{array}{l}\text { Mujeres. Premios de } \\
\text { belleza }\end{array}$ & El Sol, 11/9/1927, p.9 & Feminidad, belleza \\
\hline $\begin{array}{l}\text { Mujeres. Servicio } \\
\text { doméstico }\end{array}$ & El Sol, 18/9/1927, p.9 & Hogar \\
\hline $\begin{array}{l}\text { Mujeres. Glosa de una } \\
\text { defensa I }\end{array}$ & El Sol, 2/10/1927, p.9 & Feminidad, modernidad \\
\hline $\begin{array}{l}\text { Mujeres. Glosa de una } \\
\text { defensa II }\end{array}$ & El Sol, 9/10/1927, p.9 & Feminidad, modernidad \\
\hline Carta de Muchas 10 & El Sol, 8/1/1928, p.9 & Feminidad \\
\hline Mujeres oradoras & El Sol, 26/2/1928, p.9 & Feminidad \\
\hline $\begin{array}{l}\text { Mujeres. Lo que más nos } \\
\text { importa }\end{array}$ & El Sol, 1/4/1928, p.9 & Educación \\
\hline $\begin{array}{l}\text { Mujeres. La alcaldesa, el } \\
\text { analfabetismo y otras }\end{array}$ & El Sol, 8/4/1928, p.9 & Educación \\
\hline
\end{tabular}


cosas

Mujeres. Remachando el El Sol, 15/4/1928, p.9 Educación

clavo

Mujeres. El autor y la

El Sol, 22/4/1928, p.9

Maternidad

madre

Mujeres. La más fea y la

El Sol, 3/6/1928, p.9

Belleza

más hermosa.

Mujeres. Las damas del

El Sol, 10/6/1928, p.9

Feminidad

aire

Mujeres. Un paso atrás...

El Sol, 17/6/1928, p.9

Educación

Charlas. La otra censura

El Sol, 8/7/1928, p.10

Educación

Charlas. El poeta, la madre

El Sol, 12/8/1928, p.10

Maternidad

$y$ el niño

Al pasar. Charla, charlando

El Sol, 19/8/1928, p.10

Educación

Mujeres. "El Club de las

El Sol, 14/10/1928, p.10

Belleza

feas"

Mujeres. Unos pies

El Sol, 25/11/1928, p.10

Feminidad

diminutos

Mujeres. Nuestro

El Sol, 9/12/1928, p.10

Feminidad

monumento

Mujeres. La mujer y el

El Sol, 10/2/1929, p.10

Profesión

oficio

Mujeres. La muñeca en

El Sol, 3/3/1929, p.10

Maternidad

Rusia

Mujeres. Salomón y las

El Sol, 17/3/1929, p.10

Maternidad

madres

Mujeres. "iNo soy

El Sol, 24/3/1929, p.10

Belleza

fotogénica!"

Mujeres. Las otras Savitris

El Sol, 31/3/1929, p.10

Feminidad

Mujeres. La suerte de la

El Sol, 12/5/1929, p.10

Belleza

fea

Mujeres. Instituto de

El Sol, 26/5/1929, p.10

Belleza

belleza

Mujeres. Mamá se

El Sol, 16/6/1929, p.10

Feminidad, modernidad

divierte

Mujeres. Frente al piropo

El Sol, 28/7/1929, p.10

Educación

Mujeres. Kodak de

El Sol, 25/8/1929, p.10

Feminidad. Galicia vacaciones 


\begin{tabular}{|c|c|c|}
\hline $\begin{array}{l}\text { Mujeres. Kodak de } \\
\text { vacaciones }\end{array}$ & El Sol, 1/9/1929, p.10 & Naturaleza. Galicia \\
\hline $\begin{array}{l}\text { Kodak de vacaciones. } \\
\text { Niños al pasar... }\end{array}$ & El Sol, 8/9/1929, p.10 & Naturaleza. Galicia \\
\hline Mujeres al pasar & El Sol, 29/9/1929, p.10 & Feminidad \\
\hline $\begin{array}{l}\text { Al pie de Montjuich pasó } \\
\text { una amazona... }\end{array}$ & El Sol, 20/10/1929, p.10 & Feminidad \\
\hline $\begin{array}{l}\text { Mujeres. La raqueta, la } \\
\text { publicidad y la aguja }\end{array}$ & El Sol, 5/1/1930, p.10 & Profesión \\
\hline $\begin{array}{l}\text { Mujeres. Más reinas } \\
\text { destronadas }\end{array}$ & El Sol, 12/1/1930, p.10 & Belleza \\
\hline $\begin{array}{l}\text { Mujeres. El problema de la } \\
\text { modista }\end{array}$ & El Sol, 2/2/1930, p.10 & Feminidad, profesión \\
\hline $\begin{array}{l}\text { Mujeres. Ida, mensaje, } \\
\text { retorno... }\end{array}$ & El Sol, 2/3/1930, p.10 & Educación \\
\hline $\begin{array}{l}\text { Mujeres. Las de la } \\
\text { esperanza }\end{array}$ & El Sol, 30/3/1930, p.10 & Feminidad, modernidad \\
\hline $\begin{array}{l}\text { Mujeres. Páginas } \\
\text { femeninas }\end{array}$ & El Sol, 27/4/1930, p.10 & Feminidad, profesión \\
\hline $\begin{array}{l}\text { Mujeres. ¿Qué piensan } \\
\text { "las jóvenes"? }\end{array}$ & El Sol, 18/5/1930, p.10 & Educación \\
\hline Mujeres. Una cara nueva & El Sol, 15/6/1930, p.10 & Belleza \\
\hline $\begin{array}{l}\text { Mujeres. El arte de ser } \\
\text { suegra }\end{array}$ & El Sol, 8/2/1931, p.10 & Feminidad \\
\hline $\begin{array}{l}\text { Mujeres. Mensaje de la } \\
\text { maestra }\end{array}$ & El Sol, 3/11/1931, p.10 & Educación \\
\hline
\end{tabular}

Veamos, a continuación, las treinta y tres crónicas culturales (tabla 5) que publicó en la página femenina de $\mathrm{El} \mathrm{Sol}$ con motivo de una exposición, obra de teatro, cartel taurino, presentación de un libro o un comentario sobre moda. Fue pionera del periodismo cultural, al que se entregó completamente, hasta el punto que toda su obra periodística está impregnada de alusiones literarias, históricas, artísticas...

Al teatro y a la moda, que fueron sus aficiones preferidas, dedicó trece piezas, cuatro a los toros, para estar en contra, como lo estuvo El Sol, dos a las exposiciones, tres al libro y a las bibliotecas y dos al deporte, una actividad en alza entre las mujeres que «debería hermanarse con la inteligencia» (El Sol, 27-julio-1930, p.10) y el resto al cine y a la cultura en general. 
Con motivo de una exposición de Arte Moderno titulada "Exposición de lujo», elogia la belleza «elegante de la sencillez y la sinceridad, atributos de las personas distinguidas frente a la ostentación y las apariencias de los nuevos ricos» (EI Sol, 11-julio-1927, p.9). En una Charla referente a moda (EI Sol, 10 de julio de 1927, p.9) expone cómo ha evolucionado la moda en distintas épocas y cita a varios autores que, como ella, han escrito sobre el tema.

Lo mismo ocurre con las crónicas de teatro, escasas comparadas con su producción en otras publicaciones, por ejemplo, El Diario de Barcelona, donde tuvo sección fija. Con ocasión del centenario de Ibsen escribió cuatro piezas, en las que analiza los personajes femeninos de Casa de Muñecas (EI Sol, 15, 22, 29-julio y 5-agosto-1928, p.10), entre ellos resalta la figura de la mujer abnegada, tierna y sacrificada por amor a sus seres queridos, marido e hijos. Con las corridas de toros fue implacable, afirmaba que las mujeres que asisten pertenecen a las clases alta y baja porque las de clase media piensan que son algo exótico, bárbaro y opuesto a su sensibilidad. «No, no es cristiana la fiesta de los toros. No puede serlo el hábito de festejar el martirio de un animal y el riesgo de muerte de un hombre» (EI Sol, 11-diciembre-1926, p.9)

También hizo referencia en una crónica a las denostadas "Páginas femeninas» de los periódicos que, salvo excepciones encuentra insulsas, deslavazadas y plenas de lugares comunes. Ella propone una renovación de contenidos porque «a la lectora inteligente, viva, inquieta, moderna -o si se prefiere joven de espíritu, le interesará la marcha del país, las cuestiones literarias y artísticas, el precio del pan, el rumbo de la educación y el avance del trabajo, tanto, por lo menos, como la sección de modas...» (El Sol, 27abril-1930, p.10).

Tabla 5. Cultura

\begin{tabular}{|c|c|c|}
\hline Título & Fecha y página & Temática \\
\hline "El toro, el torero y la mujer" & El Sol, 11/12/1926, p.9 & Toros \\
\hline Charlas. Rosas de Francia & El Sol, 11/6/1927, p.9 & Cultura, exposición \\
\hline Mujeres. Eva Sikelianos & El Sol, 25/6/1927, p.9 & Cultura, exposición \\
\hline $\begin{array}{l}\text { Charlas. "Modes pour } \\
\text { dames" }\end{array}$ & El Sol, 10/7/1927, p.9 & Moda \\
\hline Modas. La invitación al viaje & El Sol, 14/8/1927, p.9 & Moda \\
\hline Charlas. Crisis de la cocina & El Sol, 28/8/1927, p.9 & Lectura \\
\hline $\begin{array}{l}\text { Charlas. Coturno y falda } \\
\text { corta }\end{array}$ & El Sol, 4/9/1927, p.9 & Moda, teatro \\
\hline Mujeres. La del torero & El Sol, 4/3/1928, p.9 & Toros \\
\hline $\begin{array}{l}\text { Charlas. La pantalla, el } \\
\text { deporte, a escena, la mujer... }\end{array}$ & El Sol, 11/3/1928, p.9 & Deporte \\
\hline Mujeres. Habla la rapsoda & El Sol, 25/3/1928, p.9 & Teatro \\
\hline
\end{tabular}


Charlas. La mujer y la biblioteca

Charlas. Las brujas, el amor, la cultura...

Después del centenario. Mujeres de Ibsen I

Después del centenario. Mujeres de Ibsen II

Después del centenario. Mujeres de Ibsen III

Después del centenario. Mujeres de Ibsen IV

Mujeres. Una conquista

Mujeres. El refajo colorado

Mujeres. La señora lee...

Mujeres. Los "aficionados"

Al pie de Montjuich.

Hablando con la señorita

"Mette"

Mujeres. Una justa

indignación

Mujeres. La evolución de la heroína...

Mujeres. Rigurosamente confidencial...

Charlas Libros para mujeres

Mujeres. Las del año treinta

Mujeres. Curvas y rectas

Modas y modos

Mujeres. El arte popular femenino

Mujeres. Estampa taurina

Mujeres. El héroe y su rival

Mujeres

Mujeres. Estudiantes 1930
El Sol, 29/4/1928, p.9

Cultura

El Sol, 6/5/1928, p.9

Cultura

El Sol, 15/7/1928, p.10

Teatro

El Sol, 22/7/1928, p.10

Teatro

El Sol, 29/7/1928, p.10

Teatro

El Sol, 5/8/1928, p.10

Teatro

El Sol, 16/2/1928, p.10

Cultura

El Sol, 20/1/1929, p.10

Toros

El Sol, 14/4/1929, p.10

Lectura

El Sol, 21/7/1929, p.10

Teatro

El Sol, 4/8/1929, p.10

Cultura

El Sol, 11/8/1929, p.10

Moda

El Sol, 18/8/1929, p.10

Cultura, cine

El Sol, 24/11/1929, p.10

Moda

El Sol, 1/12/1929, p.10

Lectura

EI Sol, 29/12/1929, p.10

Moda

El Sol, 9/2/1930, p.10

Moda

El Sol, 23/2/1930, p.10

Moda

El Sol, 4/5/1930, p.10

Educación

El Sol, 8/6/1930, p.10

Toros

El Sol, 6/7/1930, p.10

Teatro

El Sol, 27/7/1930, p.10

Deporte

El Sol, 7/9/1930, p.10 


\section{Conclusiones}

María Luz Morales, precursora del periodismo cultural y pionera de la crítica cinematográfica, escribió más de mil artículos en la prensa y cultivó todos los géneros periodísticos.

Firmó 168 crónicas en «La Mujer, el Niño y el Hogar» de El Sol, cuyos temas son: Mujer y literatura, Mujer e infancia, Feminismo, Feminidad y Cultura, similares a los de otras publicaciones femeninas, pero que ella enfoca desde su conocimiento de las grandes figuras de la literatura universal.

Dedicó cincuenta crónicas a la literatura escrita por mujeres, personajes femeninos de la literatura y biografías de mujeres ilustres. Su preocupación por la educación y la lectura de las mujeres la llevó a dirigir una encuesta que evidenció lo poco que leían, pero sirvió para despertar su interés por los libros.

Escribió diecinueve crónicas acerca de la mujer y la infancia para denunciar la "frialdad» de los Hospicios, la discriminación de los hijos naturales y abogar por la reinserción de los menores. Promovió la lectura infantil, recomendó libros apropiados para los niños y pidió a madres y maestras contaran cuentos a los pequeños.

Destinó dieciséis textos a la condición femenina y a favor de un feminismo moderado que defendiera los derechos de la mujer a una profesión, salario justo, educación, cultura y presencia en la esfera pública, pero nunca aceptó que el hombre y la mujer sean iguales.

Dedicó cincuenta crónicas a la feminidad, elogiando el rol de las madres, cuidado del hogar, arreglo personal, ejercicio de una profesión, cultivo de aficiones, deporte y moda. Habló del amor a la naturaleza, recordando su Galicia natal, y criticó los concursos de belleza porque solo valoran el aspecto físico de la mujer, no su belleza interior.

Publicó treinta y tres crónicas culturales relativas a sus dos aficiones preferidas: teatro y moda, la belleza de la sencillez, el deporte unido a la inteligencia, la condena a los toros, la renovación de contenidos de las páginas femeninas...

En suma, sin pretenderlo creó un arquetipo de mujer instruida, activa, profesional, familiar y muy femenina, que era su viva imagen. Esperamos que este trabajo tenga continuidad en investigaciones ulteriores sobre las colaboraciones de María Luz Morales en otros periódicos y revistas. 


\section{Referencias bibliográficas}

ALTÉS, E. (2007). Les periodistas del temps de la República, Barcelona, Col-legi de Periodistes.

BALAGUER, S. «María Luz Morales, premio a la lealtad acrisolada». La Vanguardia, 16junio-1971, p. 35.

CABRÉ, M. Á. (2017): María Luz Morales, pionera del periodismo, Barcelona, La Vanguardia Ediciones, S.L.

CABRERA, M. (1994): La industria, la prensa y la política. Nicolás María de Urgoiti (1869-1951), Madrid, Alianza Editorial.

DÍAZ NOSTY, B. (2020): Voces de mujeres periodistas españolas del siglo XX. Nacidas antes del final de la guerra civil, Sevilla, Renacimiento.

DOESPIRITUSANTO GALLEGO, M. (2011): O perfil dunha sombra. Achega á biografía de María Luz Morales ata 1940, Barcelona, Facultat de Comunicació Blanquerna, Universitat Ramón Llull. [Tesina de máster].

FRANCO, G. (2004). "Los orígenes del sufraguismo en España», Espacio, tiempo y forma, Serie V, Historia contemporánea, t.16, pp. 455-482. Disponible en Internet

(5-11-2020)

http://revistas.uned.es/index.php/ETFV/article/view/3085/2945

GARCÍA-ALBÍ, I. (2007): Nosotras que contamos. Mujeres periodistas en España, Barcelona, Plaza \& Janés.

GONZÁLEZ NARANJO, R. (2015): «llustres tontas y locas: el Lyceum Club de Madrid, todo un ejemplo de solidaridad femenina», en González de Sande, M., Cerrato, D., Moreno Lago, E.M. (editores), Locas: escritoras y personajes femeninos cuestionando las normas XII Congreso Internacional del Grupo de Investigación Escritoras y Escrituras, Sevilla, Alciber, pp. 721-735.

HURTADO, A. (2006): "Caterina Albert y María Luz Morales», Cuadernos Hispanoamericanos, 671, p. 43-54. Disponible en Internet (9-10-2020) http://www.cervantesvirtual.com/nd/ark:/59851/bmcm63m0

JULIO, T. (2017). «María Luz Morales, traductora: estado de la cuestión y perspectivas de investigación» en Confluenze, vol. IX, no2, pp.55-68. Disponible en Internet (17-11-2020) https://doi.org/10.6092/issn.2036-0967/7759

LUENGO, J. (2008). «Prensa femenina y mujeres periodistas. Comunicación, cultura e identidad en las representaciones de género del primer tercio del siglo XX». En 
PÉREZ-AMAT, R., NÚÑEZ, S., GARCÍA, A. (coords.) Comunicación, identidad y género. Vol I, pp. 320-330.

MANGINI, S. (2001). Las modernas de Madrid: las grandes intelectuales españolas de la Vanguardia, Barcelona, Península.

MANIFIESTO DE LAS MUJERES, Barcelona, 7-julio-1931. Disponible en Internet (15-102020) https://lyceumclubfemenino.files.wordpress.com/2018/04/manifiesto-alas-mujeres-en-espac3b1ol.pdf

MARTínEZ, C., PASTOR, R., DE LA PASCUA, M.J., TAVERA, S. (dirs.) (2000): Mujeres en la Historia de España, Barcelona, Planeta.

MARTÍNEZ-SAGI, A. (1932): "La Residencia Internacional de Señoritas Estudiantes, instalada en el que fue el Palacio Real de Pedralbes», Crónica, 28-febrero-1932, p. 8-9.

RODRIGO, A. (1996): Mujeres para la Historia. La España silenciada del siglo XX, Madrid, Compañía Literaria.

SALGADO DE DIOS, F. y LÁZARO, E. (2019): «La visión de la mujer y la feminidad en los artículos de María Luz Morales publicados en La Vanguardia (1921-1936)», Trípodos, no44, pp. 121-135. Disponible en Internet (14-11-2020)

http://www.tripodos.com/index.php/Facultat Comunicacio Blanquerna/article/view/ $\underline{622 / 711}$

SEOANE, M.C. y SÁlZ, M.D. (1998): Historia del periodismo en España. 3.El siglo XX: 1898-1936, Madrid, Alianza Editorial.

SERVÉN, C. (2010): "La labor de María Luz Morales en El Hogar y la Moda», en Escritoras y periodistas en España (1900-1939), Bernard, M. y Rota, I. (coordinadoras), pp. 87-108.

- (2012a). «Mujeres y prensa: La Página Femenina de El Sol (1917-1936)» en Actas del I Congreso Internacional «Comunicación y Género», Sevilla, 5, 6 y 7 de marzo. Sevilla, Editorial MAD, pp.1061-1074. Disponible en Internet (9-12-2020) https://idus.us.es/handle/11441/34678

- (2012b): «María Luz Morales y la promoción de la lectura infantil», Álabe, no 5, junio, pp. 1-17. Disponible en Internet (23-10-2020) http://revistaalabe.com/index/alabe/article/view/108/93

- (2013a): «Literatura, periodismo y cine: María Luz Morales en La Vanguardia», en Escritoras españolas en los medios de prensa, 1868-1936, Servén, C. y Rota, I. (editoras), Sevilla, Renacimiento, pp. 267-289. 
- (2013b): «María Luz Morales y la promoción de la lectura femenina en la Edad de Plata», en Ángela Ena Bordonada (ed.) La Edad de Plata: temas, géneros y creadores (1898-1936), pp. 251-263.

TARÍN-IGLESIAS, J. "Gran señora de nuestras letras. María Luz Morales». La Vanguardia, 21-11-1973, p.15. 